\title{
HORMONAL SEX REVERSAL IN A FEMALE
}

\author{
BY \\ W. J. MATHESON and E. M. WARD \\ From the Children's Hospital and Pathological Department, Leicester Royal Infirmary
}

(RECEIVED FOR PUBLICATION SEPTEMBER 15, 1953)

The terms pseudo-hermaphroditism and hermaphroditism have been used in different senses by various authors and for this reason they were discarded by Wilkins (1950). He describes as 'intersexes' (hermaphrodites) those cases in which the sexual dimorphism is not due to a demonstrable endocrine abnormality, and as cases of 'sex reversal' those in which there is an endocrine abnormality.

Hormonal sex reversal in the female due to congenital adrenal hyperplasia is not infrequent and is probably the commonest cause of heterosexual development (Wilkins, 1950). In most cases virilization does not start until after the external genitalia have practically completed their normal female differentiation and the anatomical abnormality is fairly uniform. Cases similar to that to be described, in which virilization appears to have started at an earlier stage of development, are most unusual and in fact only two are on record (Wilkins, quoting an unpublished case of Reilly, 1950; Schiller, 1940).

\section{Case Report}

P.C. was 10 days old on admission to the Children's Hospital, Leicester Royal Infirmary, on January 9, 1952. There had been persistent vomiting and loss of weight since birth. 'He' was the fourth child of healthy, unrelated parents born at term after an uneventful pregnancy. The infant weighed $81 \mathrm{lb}$. at birth. Of the siblings only a girl aged 10 years is alive; she has been examined and found to be a normal, healthy girl. Two brothers died in infancy, the first when he was 8 months old in another hospital. He had never thrived and vomited frequently. It has not been possible to obtain any further information about him but the mother states that all her 'boys' had the same symptoms and that 'they have all gone the same way'. The second brother died in the Leicester Royal Infirmary at the age of 4 weeks; he also suffered from persistent vomiting and loss of weight. On the day before death alkali reserve was 40 volumes $\%$ and serum chlorides $88 \mathrm{mEq}$. per litre. At necropsy no cause of death other than bronchopneumonia was found. Idiopathic renal acidosis had been considered as a possible diagnosis but the biochemical findings did not support this and no calcification was found in the renal tubules.
On admission P.C.'s temperature was $99^{\circ} \mathrm{F}$., pulse rate 140 and respirations 36 per minute. Weight was $6 \mathrm{lb}$. $13 \mathrm{oz}$. Apart from signs of loss of weight and dehydration, no other definite abnormality was found except that the penis appeared large for the child's age.

Urine was tested on January 8 and January 11 when a small amount of protein was found. A chromatogram (Dr. Bickel) on January 24 showed no abnormal excretion of amino-acids, but traces of fructose and lactose. A specimen of urine on February 4 showed no cystine crystals, but glucosazone was obtained. Serum chlorides on January 12 were $90 \mathrm{mEq}$. per litre; on January 22, $98 \mathrm{mEq}$; ; and on February 4, $55 \mathrm{mEq}$.

Tests for blood urea on January 12 gave $64 \mathrm{mg} . \%$ and $80 \mathrm{mg} . \%$ on February 4.

An intramuscular pyelogram on January 15 was abandoned because the kidney was obscured by gas in the intestine on a straight film.

Feeds were taken fairly well but there was little gain in weight which fluctuated between extremes of 7 and $61 \mathrm{lb}$. The baby vomited at least once or twice a day and dehydration, frequently out of proportion to the vomiting, necessitated the administration of normal saline subcutaneously in amounts of $4 \mathrm{oz}$. once or twice daily. Terminally there were signs of bronchopneumonia: The infant died on February 10, 1952, at the age of 6 weeks.

Apart from the parenteral saline, DOCA was given daily intramuscularly in doses of $2 \mathrm{mg}$. from February 4 without apparent benefit.

Originally a diagnosis of an inborn error of metabolism was considered, but Fanconi's syndrome was suggested by the finding of albuminuria and glycosuria although there was no abnormal excretion of amino-acids. Serum chloride levels were not at first considered to be sufficiently low to justify a diagnosis of adrenal cortical hyperplasia with insufficiency (blood samples taken for potassium estimation were unfortunately haemolysed) but latterly there was a considerable fall and this was the final clinical diagnosis; the glycosuria found was probably due to the adrenal dysfunction.

Necropsy Report.-The body was that of a very emaciated infant. The external genitalia appeared to be those of a normal male; the external urinary meatus opened at the tip of the glans and the scrotum was normal in size and appearance but contained no testes (Figs. 1 and 2). In the abdomen both adrenal glands were very large, weighing together $18 \mathrm{~g}$. There was a well 
formed uterus lying in its normal position with Fallopian tubes, ovaries and round ligaments on each side. The uterine cervix was of normal appearance and the upper four-fifths of the vagina well formed and of normal calibre; the lower fifth was very narrow and would only admit a probe which passed through to open into the

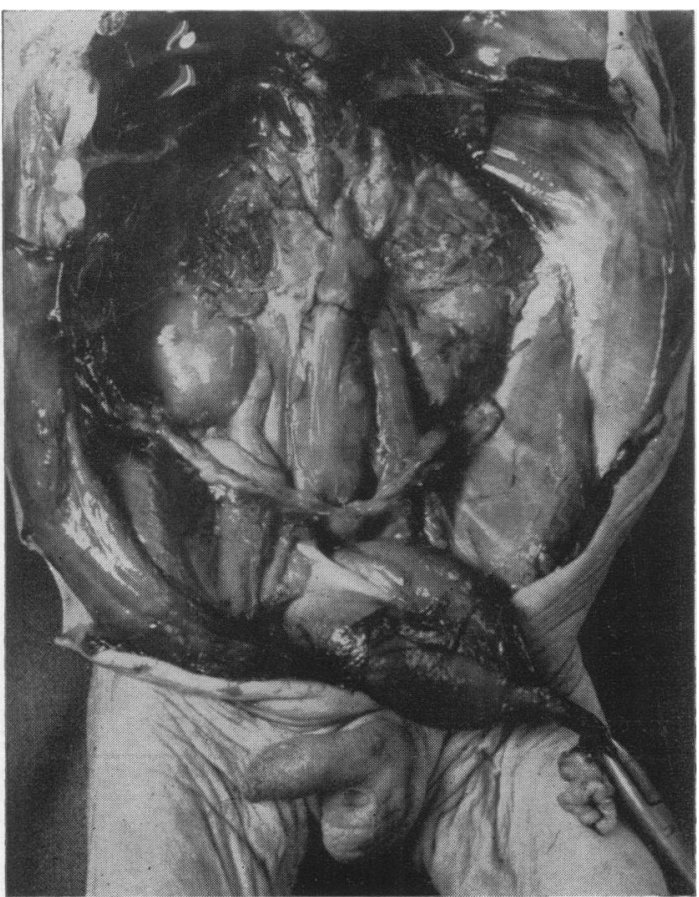

Fig. 1.-Post-mortem photograph of abdominal viscera.

posterior urethra at the verumontanum (Fig. 3). In the angle between the superior surface of the vagina and the posterior surface of the urethra lay a prostate.

There was bilateral hydro-ureter, more marked on the left than the right. There were well marked mucosal valves in the posterior urethra below the verumontanum and the bladder was hypertrophied.

There was bronchopneumonia of both lungs.

Adrenal Gland. Microscopically the zona glomerulosa is very thin, consisting only of two or thrze rows of compressed cells. The zona fasciculata is well shown but the main mass of the cortex consists of a zona reticularis (Fig. 4). In the fuchsin-stained section (Fig. 5) most of the cells of the zona reticularis are stained deeply.

Penis. Cross-section shows the urethra lying in the centre of the corpus spongiosum with the joined corpora spongiosa above.

OVARY. There are a large number of tiny graafian follicles but others are developing and show well marked discus proligerus. The largest is $8 \mathrm{~mm}$. in cross section in the fixed specimen (Fig. 6).

Prostate. The acini are small and are lined by a

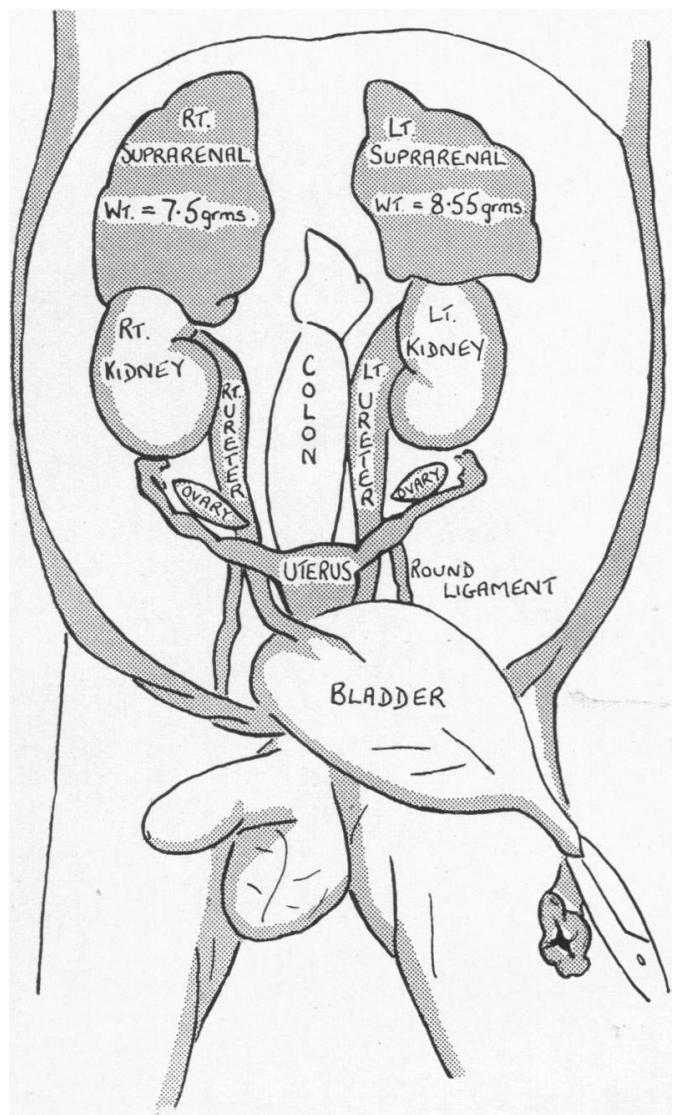

FIG. 2.-Diagrammatic representation of Fig. 1.

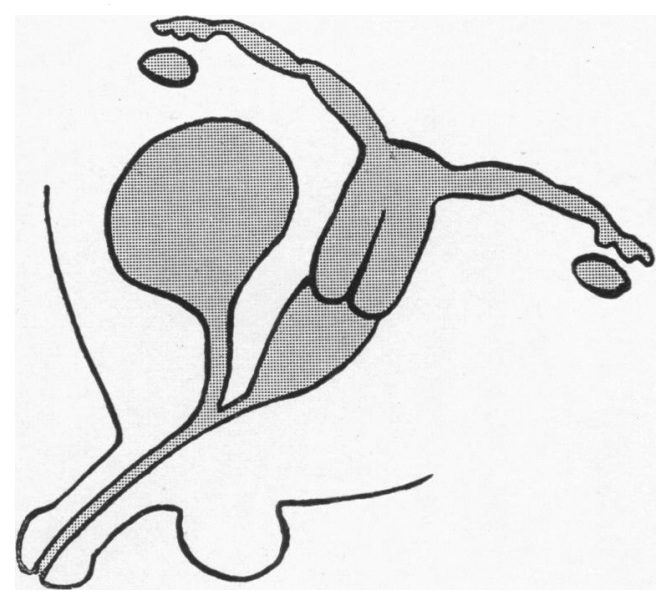

FIG. 3.-Diagrammatic cross-section to show relationship of vagina and urethra. 


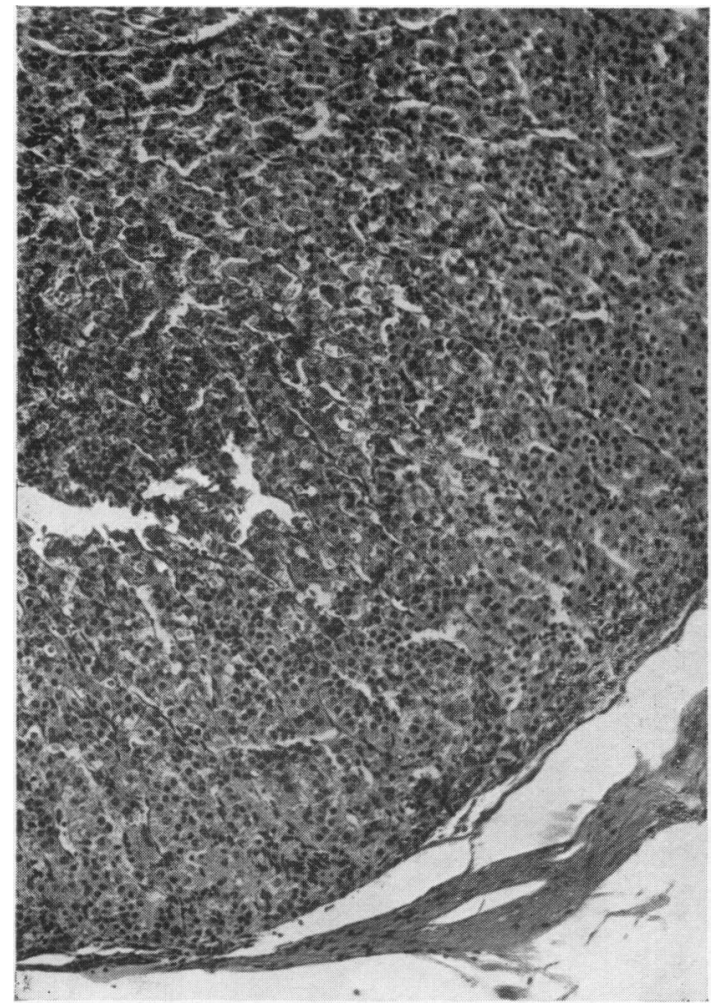

FIG. 4.-Section of adrenal cortex (haematoxylin and eosin $\times 90$ ) showing narrow band of zona glomerulosa and wide bands of zona fasciculata and reticularis.

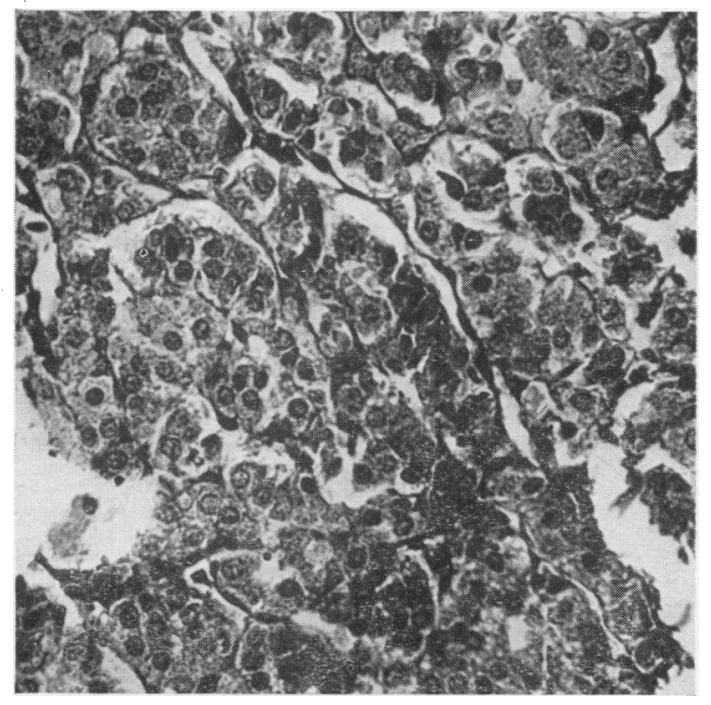

FIG. 5.-Section of adrenal cortex (Ponceau-fuchsin $\times$ 235) showing the darkly stained granules in the cells of the zona reticularis.

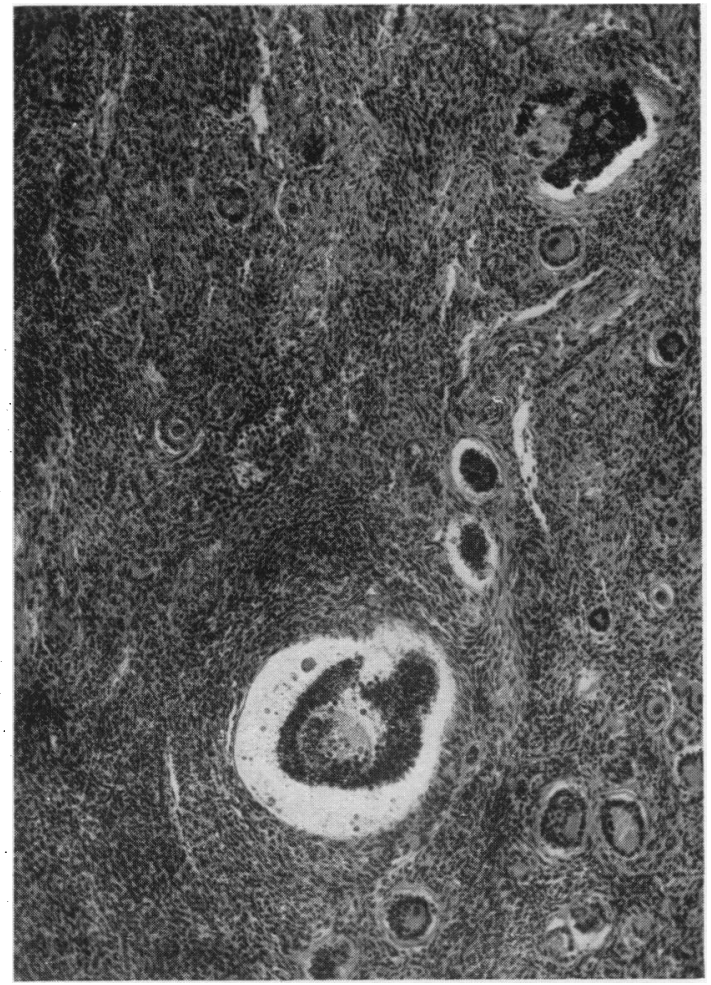

FIG. 6.-Section of ovary (haematoxylin and eosin $\times 90$ ) showing large number of undeveloped and several developing follicles.

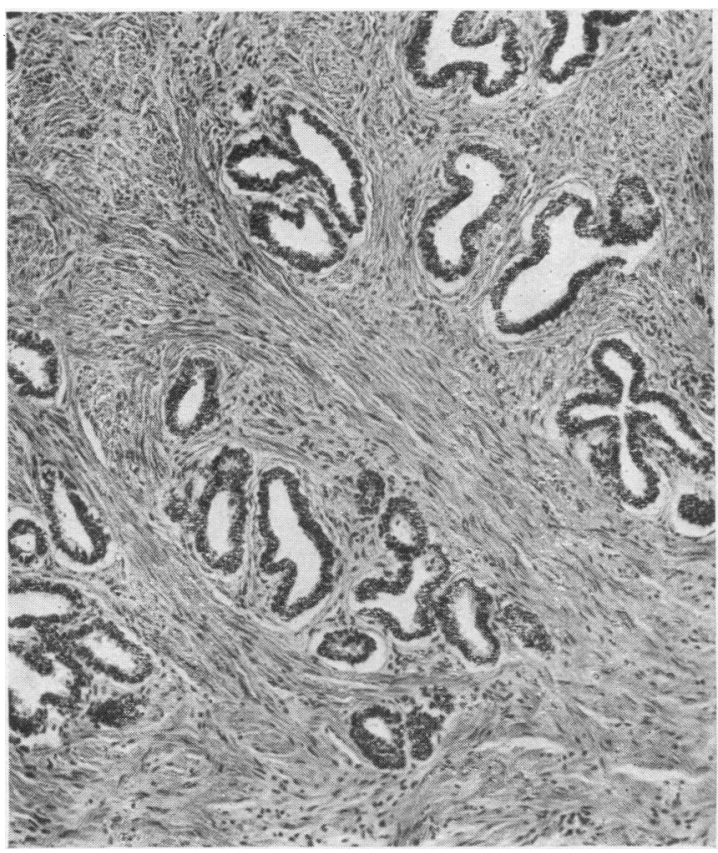

FIG. 7.-Section of prostate (haematoxylin and eosin $\times 90$ ) showing normal architecture of the gland. 
double row of cubical epithelium; they lie in a musculofibrous stroma. No corpora amylacea can be identified (Fig. 7).

\section{Discussion}

The human embryo is potentially bisexual up to about the $25 \mathrm{~mm}$. crown-rump stage (52 days) when the primitive gonad develops into a testis or ovary (Hamilton, Boyd and Mossman, 1952). Even for some time after this male and female development follows similar lines; thus the para-mesonephric (Mullerian) duct system is identical in male and female up to the $27 \mathrm{~mm}$. (54 days) stage and the development of the urethra in both sexes follows a similar pattern up to about the $38 \mathrm{~mm}$. (65 days) stage. By about the $45 \mathrm{~mm}$. stage (70 days) the male external genitalia reach approximately their final form, that is to say the urethral folds, which in the female become the labia minora, have fused as far as the glans to form the urethral tube. The labioscrotal swellings, however, do not finally fuse to form the scrotum until about the $55 \mathrm{~mm}$. stage $(77$ days). The duct system is the last to reach its final form; the mesonephric (Wolffian) duct begins to degenerate in the female at about the $30 \mathrm{~mm}$. stage but traces persist up to the $70 \mathrm{~mm}$. stage and in some cases for longer. The para-mesonephric duct in the female is not fully differentiated until the $150 \mathrm{~mm}$. stage (110 days) when the uterine portion of the utero-vaginal canal becomes separated from the vaginal; the urethral and vaginal orifices do not become separated finally until the $162 \mathrm{~mm}$. stage (118 days).

Sex Determination.-It is generally agreed that sex is genetically determined and that hormones execute a pre-determined plan (Hoffman, 1944). When, however, each phase begins and ends is a matter of controversy. The two extreme views may be represented by, on the one hand, the belief that the gonads, ducts and external genitalia are entirely genetically determined (Moore, 1947) and that the function of hormones is to complete sexual maturity post-natally; on the other hand it is held by others that genetic influences determine whether the primitive gonad develops into a testis or ovary which then, by elaboration of hormones, influences further development along male or female lines (Greene, 1942). It is undeniable that sexual development can be influenced by hormones; this is seen in nature in the case of freemartins where the female twin is masculinized in utero by the male. Raynaud and Frilley (1947) destroyed the gonads of embryo mice aged 13 days by means of $x$ rays and found that the development of females was unaffected but that males tended to develop along female lines. Similar results were obtained by Jost (1947) in the rabbit. It is suggested that, in the absence of embryonic testicular hormone, development proceeds along female lines through the influence of maternal oestrogen and, as a corollary, that the embryonic testis must produce sufficient hormone to counteract the effect of maternal oestrogen if the individual is to develop into a male (Wilkins, 1950). This hypothesis and the experiments on which it is based cannot be applied unreservedly to normal human development but it receives some support from two observations; first, that in the male a greater number of Leydig cells are present in the testis early in pregnancy when sexual development is taking place than later, and secondly that in ovarian agenesis the sexual characters are well defined (Schiller, 1940). The syndrome of ovarian agenesis could be used as an argument that sex is entirely genetically determined if a similar condition of testicular agenesis occurred in the male; such a condition, has, however, never been reported (Wilkins, 1950). The fact that sexual development can be influenced by hormones shows that embryonic tissues are responsive to them and makes it likely that hormones play a part in normal intrauterine development.

Sex of Present Case. - Of the two similar cases described, Wilkins (1950) considered his to be a female and Schiller (1940) his a male. We believe that our case was a female because the gonads were ovaries, the prostate was of female type (Young, 1937) and the anatomical pattern is explicable as that of a genetic female virilized.

But for the findings of large adrenals this case might be considered an 'intersex' due to a genetic aberration. Cases of feminization in the adult male due to adrenal tumours are described (Schiller, 1940) and it is arguable that this case could be a feminized male. No such case has, however, been described at this age, and according to Wilkins in all cases of sex reversal in which the gonads were ovaries there was evidence of excessive production of androgens.

In most cases of hormonal sex reversal in the female due to congenital adrenal hyperplasia the anatomical abnormality is fairly constant; the vaginal and urethral orifices are not separate but form a persistent urogenital sinus which opens below a hypertrophied clitoris resembling a hypospadic penis. The para-mesonephric duct system develops normally to form Fallopian tubes, uterus and vagina and the gonads are, of course, ovaries. This anatomical pattern suggests that the virilizing effects of the adrenal begin to exert an influence on development some time after about the $50 \mathrm{~mm}$. stage when the external genitalia have undergone male or female 
differentiation and before the $162 \mathrm{~mm}$. stage when the urethral and vaginal orifices become separate (Wilkins, 1950).

Anatomically the interesting and unusual features of this case are the complete masculinization of the external genitalia, the presence of posterior urethral valves and of the prostate.

The External Genitalia.--The penis and scrotum were perfectly formed except that the scrotum contained no testicles. The urethra had a central terminal opening on the glans. The penis appeared to be larger than the average at this age (Fig. 1) and it is interesting to reflect that, had this child lived, she would have appeared externally to be a sexually precocious male.

Posterior Urethral Valves. - These were sufficiently well marked to cause urinary stasis. Higgins, Williams and Nash (1951) suggest that these valves are formed by excessive development and adhesion of the medial edges of the lateral submontal folds of mucous membrane which are seen normally from the $60 \mathrm{~mm}$. stage onwards in the male. It is uncertain if they ever occur in the normal female in whom their presence would be inexplicable on embryological grounds since the female urethra corresponds only to the supramontal part of the urethra in the male.

Prostate. - The prostate consisted only of a middle lobe, i.e., it was related only to the 'supramontal' part of the urethra. In the male the prostate begins to develop at about the $55 \mathrm{~mm}$. stage from buds which grow out of the urethra; the posterior lobe is derived from inframontal buds. In the female these urethral buds form the para-urethral glands and glands of Skene (Hamilton, Boyd and Mossman, 1952). In virilized females prostates may develop but there is never a posterior lobe (Young, 1937). This is to be expected on embryological grounds since the female urethra corresponds only to the supramontal part in the male, but it is surprising that the prostate was not fully developed in this case. The only explanation appears to be that genetic influences were sufficiently strong to prevent this. It is of interest that the male and female parts of the prostate maintain their differences in susceptibility to disease, since it is the posterior lobe which is more frequently involved in malignant disease and the middle lobe in prostatic hypertrophy (Young, 1937).

The adrenal cortex develops early and its growth is rapid so that it is already a relatively large structure by the $12 \mathrm{~mm}$. stage. Since congenital adrenal hyperplasia is not infrequently found in more than one member of a family (Wilkins, 1950), and it is possible that the two brothers suffered from this condition, it seems likely that the adrenal cortex in this case was hyperplastic from the start and thus could exert a virilizing effect from the earliest possible moment. Virilization in this case began before the $45-50 \mathrm{~mm}$. stage since the genitalia were of male form. Before this time, apart from the presence of a testis or ovary, the embryo is virtually bisexual.

Both brothers suffered from symptoms suggestive of adrenal insufficiency and it seems possible that they died, as the patient did, as a result. Cases of adrenal cortical hyperplasia with excessive production of androgens but diminished secretion of hormones controlling salt and water metabolism producing a picture like Addison's disease are well recognized and appear to be more common in the male than in the female; of 83 cases of hormonal sex reversal in the female only six showed signs of adrenal insufficiency, while of 16 cases of congenital adrenal hyperplasia in the male, 10 had symptoms of adrenal insufficiency (Wilkins, 1948). In neither brother was this diagnosis proved. The first died in another hospital and it has not been possible to obtain any details about him; the second died in this hospital, no convincing cause of death being found at necropsy. It is notoriously easy to overlook adrenal hyperplasia with insufficiency in the male; moreover the adrenals at 3 weeks (when he died) are normally large and pathological enlargement could thus easily pass unnoticed, particularly since they were neither weighed nor sectioned.

It may seem contradictory that virilization in this case was capable of altering the external genitalia to masculine but could not prevent the normal female differentiation of the para-mesonephric ducts. One possible explanation for this appears to be that the external genitalia are responsive to both testicular and adrenal androgen but that the para-mesonephric duct is only responsive to oestrogen or testosterone. If it is agreed that normal intra-uterine development is influenced by hormone secreted by the embryonic testis or ovary, it follows that the para-mesonephric duct system develops in the female under the influence of oestrogen and retrogresses in the male with testosterone; it has not, however, been postulated that it is responsive to adrenal androgen. The external genitalia, however, may be responsive to both adrenal and testicular androgen; in the adult female virilized by an adrenal tumour the external genitalia alone of the sexual organs are visibly altered. In this case the external genitalia might have been altered to the male form by adrenal androgen while the paramesonephric duct system developed normally under the influence of oestrogen secreted by the ovary. 


\section{Summary}

A case is described of congenital adrenal hyperplasia in which there were male external and female internal genitalia. The gonads were ovaries. There was a prostate and posterior urethral valves causing urinary stasis.

It is suggested that virilization began at a much earlier stage of development than is usual in hormonal sex reversal but that the para-mesonephric duct system developed normally because it is unresponsive to adrenal androgen.

We wish to thank Professor W. D. Newcomb and Dr. J. G. Bate for their help with the histology, Professor
F. Goldby for his advice about the embryology, Dr. H. Jolly for advice and Mr. E. V. Willmott for the microphotographs.

\section{REFERENCES}

Greene, R. R. (1942). Biol. Symposia, 9, 105.

Hamilton, W. J., Boyd, J. D. and Mossman, H. W. (1952). Human Embryology, 2nd ed. Cambridge.

Higgins, T. T., Williams, D. I. and Nash, D. F. E. (1951). The Urology of Childhood. London.

Hoffman, J. (1944). Female Endocrinology. Philadelphia.

Jost, A. (1947). Arch. anat. micr. Morph. exp., 36, 271

Moore, C. R. (1947). Embryonic Sex Hormones and Sexual Differentiation. Springfield.

Raynaud, A. and Frilley, M. (1947). Ann. Endocr., Paris, 8, 400.

Schiller, W. (1940). Int. Clin., 3, 86.

Wilkins, L. (1948). Advanc. Pediat., 3, 159. New York. (1950). The Diagnosis and Treatment of Endocrine Disorders in Childhood and Adolescence. Springfield.

Young, H. H. (1937). Genital Abnormalities Hermaphroditism and Related Adrenal Diseases. Baltimore. 